This is a non-peer reviewed preprint submitted to EarthArxiv

\title{
Description of the continuous nature of organic matter in models of soil carbon dynamics
}

\author{
Sainte-Marie Julien ${ }^{* 1,2,3}$, Barrandon Matthieu ${ }^{4}$, Saint-André Laurent ${ }^{2,3}$, Gelhaye Eric ${ }^{5,3}$, \\ Martin Francis ${ }^{5,3}$, and Derrien Delphine ${ }^{2,3}$ \\ ${ }^{1}$ Université de Lorraine, AgroParisTech, INRAe, SILVA, F-54000 Nancy, France \\ ${ }^{2}$ INRAe, BEF, F-54000 Nancy, France \\ ${ }^{3}$ Laboratory of Excellence ARBRE, F-54000 Nancy, France \\ ${ }^{4}$ Université de Lorraine, CNRS, IECL, F-54000 Nancy, France \\ ${ }^{5}$ Université de Lorraine, INRAe, IAM, F-54000 Nancy, France \\ * corresponding author: juliensaintemarie@gmail.com
}

\begin{abstract}
The understanding of soil organic matter (SOM) dynamics has considerably advanced in recent years. It was previously assumed that most SOM consisted of recalcitrant compounds, whereas the emerging view considers SOM as a range of polymers continuously processed into smaller molecules by decomposer enzymes. Mainstreaming these new insights in current models is challenging because of their ill-adapted framework. We propose the C-STABILITY model to resolve this issue. Its innovative framework combines compartmental and continuous modelling approaches to accurately reproduce SOM cycling processes. Model theoretical simulations highlight the role of SOM accessibility on its turnover. They reveal how enzyme depolymerization, decomposer community succession and carbon use efficiency are key drivers of SOM composition and quantity during decomposition and at steady-state. The mathematical structure of C-STABILITY may be tailored to different scales and is open to alternative formulations, thus offering a promising foundation for enhancing carbon cycling predictions.
\end{abstract}

\section{Keywords}

carbon dynamics; model; enzyme depolymerization; microbe functional diversity; accessibility. 


\section{Introduction}

Soil organic matter (SOM) is the largest reservoir of organic carbon (C) on land (Lehmann and Kleber, 2015). Understanding and modeling the processes driving its dynamics is essential to predict SOM response to changes in climatic conditions and human land management, and its contribution to soil functions and climate mitigation.

Our view of the nature of SOM and decomposition pathways has recently been challenged by the wealth of information generated by new analytical techniques (Blankinship et al. 2018). It was previously assumed that most SOM consisted of recalcitrant litter material and humic molecules formed by the condensation of decaying substrates. The emerging view is now that SOM occurs as a range of organic compounds continuously processed into smaller molecules by microorganisms through the production of extracellular enzymes (Lehmann and Kleber, 2015). Under this new SOM cycling paradigm the local environment is seen a critical driver of SOM decomposition as it determines its physicochemical accessibility to extracellular enzymes and modulates microbial metabolism (Kemmitt et al., 2008; Schmidt et al., 2011, Schimel and Schaeffer, 2012, Dungait et al. 2012).

Metabolic activity of microbes consists of catabolism, in which extracellular enzymes depolymerize SOM, and anabolism, which is responsible for $\mathrm{CO}_{2}$ emissions and biochemical transformation of assimilated compounds. The biosynthesized microbial metabolites are known to strongly interact with protective mineral surfaces and may be sequestered for a long time in the soil (Schimel and Schaeffer, 2012, Cotrufo et al. 2015 Liang et al. 2017, 2019). In the last decade new information on the functional diversity of microbial communities and on their catabolic action has become available. Genome analyses notably enable characterization of the enzyme sets encoded by each decomposer species and classification of decomposer taxa into functional guilds (Eastwood et al., 2011, Floudas et al., 2012, Riley et al., 2014, Kohler et al., 2015, Talbot et al. 2015; Nagy et al., 2016). Enzymes production patterns can now be monitored over time via proteome and secretome analyses (Zhang et al., 2016, 2019).

How have models of SOM dynamics evolved in recent years to incorporate novel knowledge and theories? A number of new compartment models better representing microbial ecology processes have been proposed (Todd-Brown et al., 2012, Sulman et al., 2018). The most often incorporated features include decomposer physiological factors (substrate use efficiency, growth and mortality rates, etc.) and extracellular enzyme properties such as production rate, catalytic properties, etc. (Moorhead and Sinsabaugh, 2006, Allison, 2012 Kaiser et al. 2015). The microbial response to fluctuating environmental parameters such as temperature 
and nitrogen availability is also sometimes integrated (Treseder et al., 2012). Some models explicitly describe how the soil spatial microarchitecture governs decomposer access to substrates (Monga et al. 2014 Vogel et al., 2015 Kaiser et al., 2015) or specify the SOM protection mechanism (Wieder et al., 2014, Abramoff et al., 2018). Yet these compartment models are limited because they assume that SOM can be represented as a few discrete pools with differing turnover times (Blankinship et al. 2018). They do not describe the continuum of SOM at different stages of decay. Hence they cannot reproduce how enzyme functional diversity and decomposer ecology regulate $\mathrm{C}$ turnover through the progressive depolymerization of SOM until it becomes accessible for uptake and subsequent assimilation or mineralisation. Besides, the description of a large number of compounds and processes leads to model prediction uncertainty (Shi et al., 2018).

In contrast to compartment models, continuous models have received little attention from developers in recent years. Existing models represent SOM as a distribution along a quality axis and describe how organic matter (OM) quality evolves towards more recalcitrant - or stable - stages as decomposition progresses, without a detailed description of microbial and biogeochemical mechanisms (Agren et al., 2017, 2018, Bartsev and Pochekutov, 2019, Menichetti et al., 2019). At first glance, they seem particularly appealing for representing the current view of SOM as a range of heterogeneous organic compounds at different decomposition stages with few parameters. But they have three major shortcomings. First, quality is viewed as an intrinsic property of OM, generally in line with the outdated recalcitrance notion. Second, quality is a concept defined relative to a uniform decomposer group, which is at steady-state in existing models what is not realistic. These two characteristics hinder the investigation of issues related to functional ecology and decomposer community succession. Third, the notion of quality is complex, not measurable and this abstraction is a major barrier to wide acceptance of the continuum approach.

Here we propose a new general model of SOM dynamics combining advantages and suppressing drawbacks of the current compartment and continuum quality models. This Carbon Substrate Targeted AccessiBILITY (C-STABILITY) model is driven by microbial activity and combines compartmental and continuous approaches. The substrate is split into biochemical classes, separating pools accessible to enzymes from inaccessible ones (Figure 1a). Within each pool a continuous approach is implemented to describe the level of substrate polymerization (Figure 1b). Enzyme action and microbe uptake are targeted to specific chemical forms of the substrate, depending on its biochemistry and physicochemical accessibility. The model distinguishes between substrate accessibility to microbe uptake, only possible for lowly polymerized molecules, and substrate accessibility to enzymes regulated by OM spatial arrangement within the soil matrix or interactions with other soil components (Rowley et al., 2018). Over time the enzyme-accessible substrate is fragmented 
(a) C-STABILITY conceptual diagram

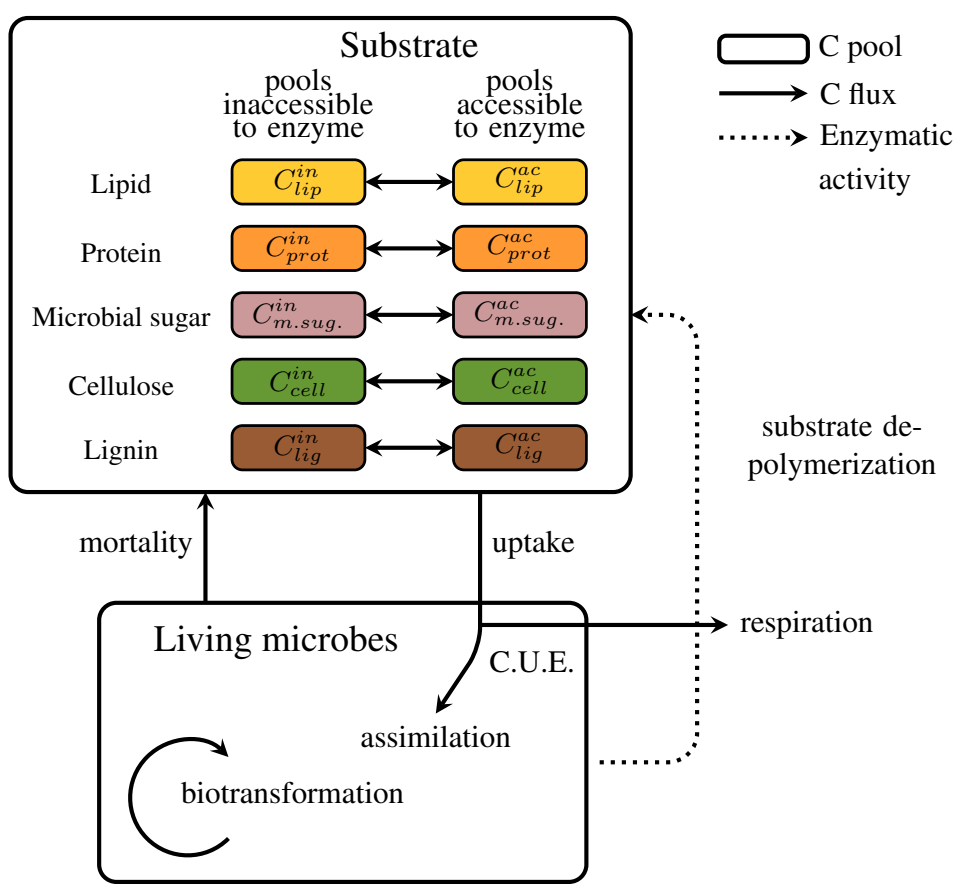

(b) Substrate polymerization description for an accessible pool

accessible to microbe uptake

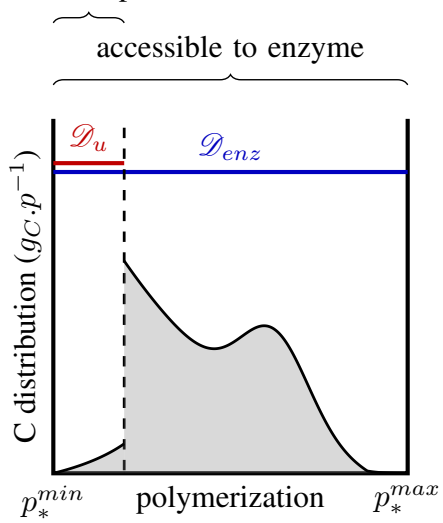

Figure 1: C-STABILITY model framework. (a) Conceptual diagram of the C-STABILITY model. Colored boxes stand for substrate $\mathrm{C}$ pools. The colors represent the different biochemical classes, and forms accessible to enzymes are separated from inaccessible ones. Plain arrows represent fluxes, the dotted arrow represents enzymatic activity. C.U.E. means carbon use efficiency. (b) For each biochemical class (denoted $*$ ), a continuous distribution reports the polymerization level of the substrate. $p_{*}^{\min }$ and $p_{*}^{\max }$ are the maximum and minimum levels of polymerization. The polymerization axis is oriented from the lowest polymerization level on the left to the highest polymerization level on the right. The blue domain $\left(\mathcal{D}_{\text {enz }}\right)$ identifies polymers accessible to enzymes. The red domain $\mathcal{D}_{u}$ identifies monomers and small oligomers accessible to microbe uptake. The amount of $\mathrm{C}$ corresponds to the area below the curve.

and depolymerized until it eventually becomes accessible to microbe uptake. Part of the absorbed substrate is assimilated by decomposers and its biochemistry is modified by decomposer anabolism. This is accounted for in the model by the redistribution of decomposer necromass into the various substrate biochemical pools upon the death of the decomposer (Figure 1). One of the major features of the model is the description of the enzymatic polymer breakage process. A substrate cleavage factor, $\alpha_{\text {enz }}$, is introduced for each enzyme family (e.g. cellulolytic, proteolytic, etc.) to indicate if it depolymerises the substrate by cleaving its end-members or if it randomly breaks any bond (Figure 2). This general model enables accurate and parsimonious representation of the SOM nature and degradation pathways as they are currently understood. It notably describes the continuum of organic forms generated by enzyme depolymerization, i.e. which no current SOM compartment model has achieved to date. 
(a) Impact of enzyme cleavage on shift in substrate polymerization

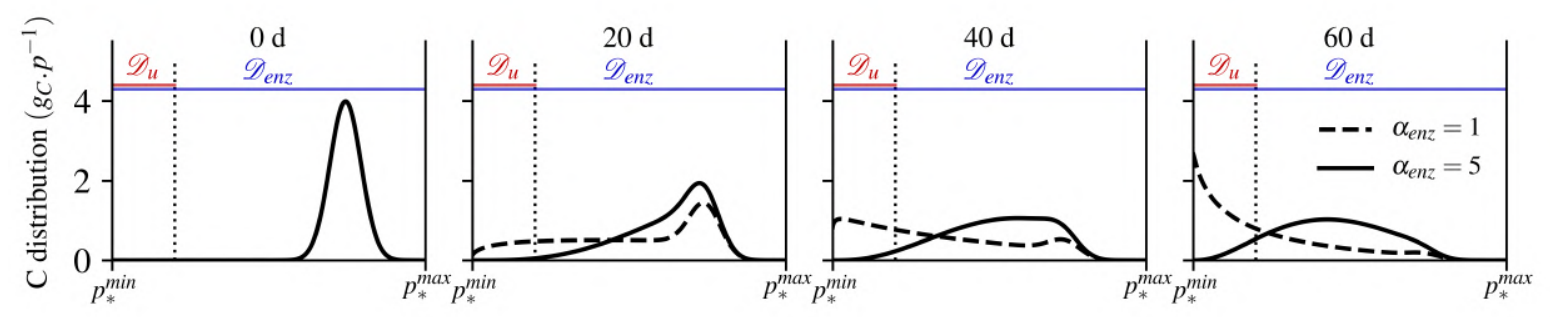

(b) Schematic representation of enzyme cleavage

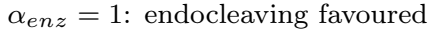

$\alpha_{e n z}=1$ : endocleaving favoured

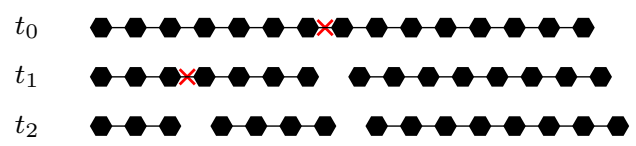

$\alpha_{e n z}=5$ : exocleaving favoured

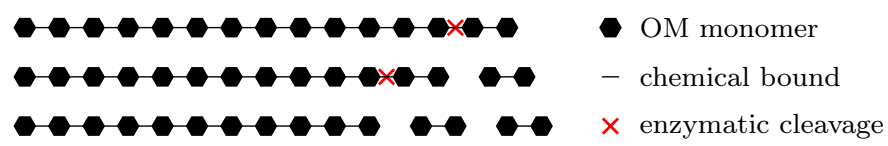

Figure 2: Change in substrate polymerization over time induced by enzymes for a specific accessible biochemical class $($ denoted $*)$. The $\mathcal{D}_{\text {enz }}$ domain (blue) indicates substrate accessible to its enzymes. $p_{*}^{\text {min }}$ and $p_{*}^{\text {max }}$ are the maximum and minimum levels of polymerization. The $\mathcal{D}_{u}$ domain (red) indicates where the substrate is accessible for microbe uptake. Here the microbe uptake rate is nil, which explains the substrate accumulation in $\mathcal{D}_{u}$. Two substrate cleavage factor $\alpha$ values are tested. $\alpha_{e n z}=1$ is typical of the action of endocleaving enzymes, which randomly disrupt any substrate bond and generate oligomers, inducing a rapid shift towards the $\mathcal{D}_{u}$ microbial uptake domain. $\alpha_{e n z}=5$ is typical of exocleaving enzymes attacking the substrate end-members to release small oligomers, inducing a slower shift towards $\mathcal{D}_{u}$.

In this article, we explore C-STABILITY predictions by investigating four scenarii inspired by current keyquestions and designed on the basis of a wide range of recent publications. First, we examine the sensitivity of the model parameters in a simple case of cellulose decomposition to show how enzyme cleavage impacts the substrate uptake by decomposer. Second, we simulate lignocellulose decomposition to illustrate how substrate accessibility to enzyme is regulated. Third, we investigate how the succession on a substrate of different functional microbe communities affects its biochemistry during decomposition. Fourth, we run the model at steady-state in a soil continuously supplied with lignocellulose and subjected to microbial recycling to determine if microbial biomass is the dominant SOM source. Finally, we discuss how the innovative C-STABILITY framework offers an attractive opportunity to improve the description and prediction of C cycling in soil. 


\section{Results}

\subsection{Depolymerization pattern as a major driver of organic matter uptake by microbe}

We ran a first scenario to illustrate how substrate accessibility to microbe uptake is regulated by enzyme catalytic activity. A cellulose polymer subjected to the cellulolytic action of a set of enzymes was split into smaller fragments, which corresponded to a gradual decrease in the cellulose polymer size distribution towards short oligomers in the microbial uptake domain, $\mathcal{D}_{u}$ (Figure 3a). With the chosen parameters (supplementary table), $95 \%$ of the cellulose-C was consumed after 123 days, with a mean residence time

(a) Changes in cellulose polymerization distribution over time
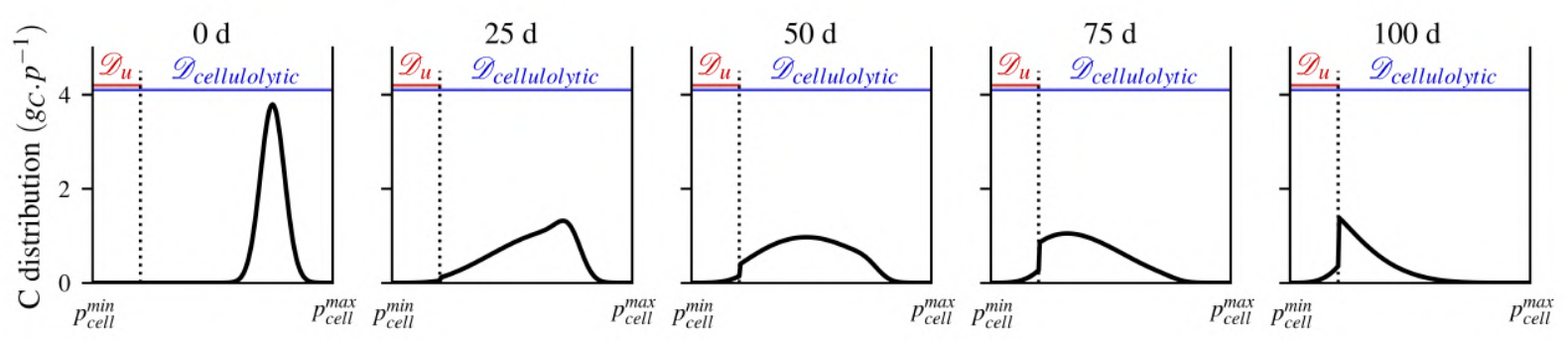

(b) Changes in $\mathrm{C}$ stocks during cellulose degradation

(c) Parameters affecting the amount of residual cellulose
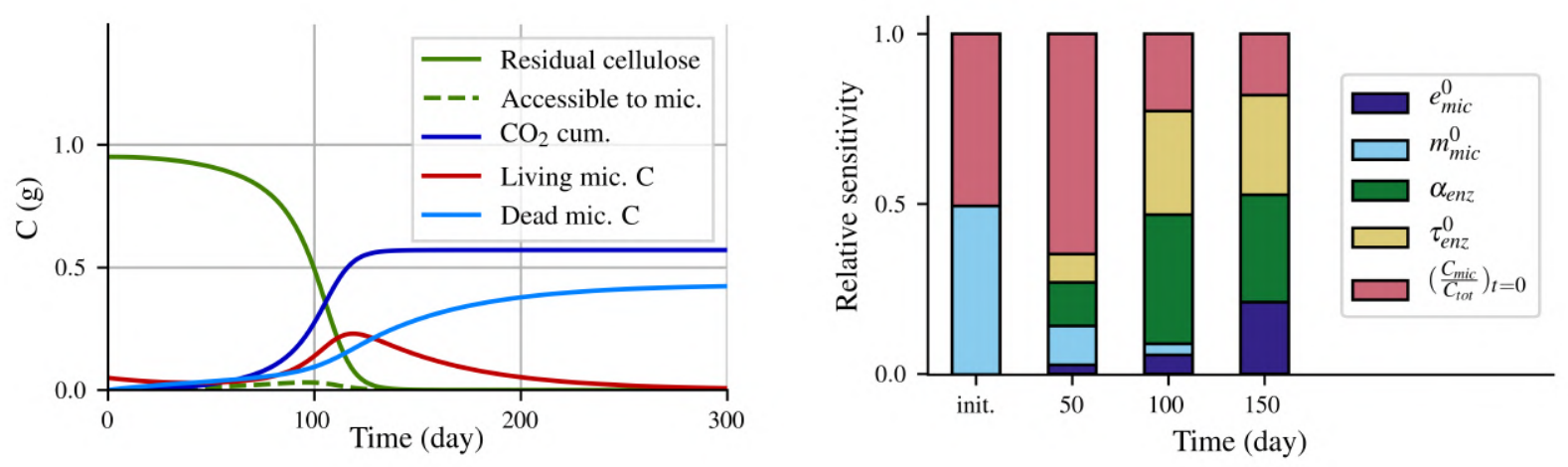

Figure 3: Dynamics of cellulose degradation by one decomposer community (scenario 1). (a) Changes in the distribution of cellulose polymer length over time. The $\mathcal{D}_{\text {cellulolytic }}$ domain (blue) is indicative of cellulose accessible to cellulolytic enzymes, the $\mathcal{D}_{u}$ domain (red) is indicative of cellulose oligomers accessible for microbe uptake; $p_{\text {cell }}^{\text {min }}$ and $p_{c e l l}^{\max }$ are the maximum and minimum levels of cellulose polymerization. (b) Amount of residual cellulose-C, C available for microbial uptake, cumulated $\mathrm{CO}_{2}$, living biomass-C and dead microbial residues-C. There is no microbial recycling in this simulation. Note that the sum of cellulose- $\mathrm{C}$ and living microbes-C at the beginning is equal to the sum of cumulated $\mathrm{CO}_{2}$ and microbial residues-C at the end; (c) Sensitivity analysis on the amount of residual cellulose-C $\left( \pm 5 \%\right.$ uniform variability). Variance fractions are explained by the carbon use efficiency $e_{m i c}^{0}$, mortality rate $m_{m i c}^{0}$, substrate cleavage factor $\alpha_{e n z}$, enzyme activity rate $\tau_{0}$ and initial microbial-C to total-C ratio. 
of 97 days, which was consistent with results of laboratory incubation studies, e.g. Skyba et al. (2013). Note that during the first 25 days the enzyme action mostly generated oligomers that were too large to be accessible for microbe uptake (Figs. 3a and 3b), inducing a decrease in the living microbe biomass. The influence of the parameters on the amount of residual cellulose varied over time (Figure 3c). As the decomposition dynamics were driven by microbes, any modification affecting the size of their biomass had a marked impact on the residual cellulose. Thus the mortality rate $m_{m i c}^{0}$ and the initial $C_{m i c} / C_{t o t}$ ratio had a strong influence at the beginning of the simulation, while the microbial carbon use efficiency $e_{m i c}^{0}$ was a sensitive parameter at the end of the simulation. The enzymatic substrate cleavage factor $\alpha_{e n z}$ and enzyme action rate $\tau_{\text {enz }}^{0}$, which controlled the amount of substrate available to microbes, became crucial parameters once the microbe community started growing. The decrease in the $\alpha_{e n z}$ value induced a faster depolymerization pattern and made the substrate accessible for decomposer uptake more rapidly (Figure 2). $\alpha_{e n z}$ indeed indicated whether the enzyme preferentially catalysed substrate end-members (exo-cleaving enzyme - high $\alpha_{e n z}$ values) or randomly disrupted any substrate linkage (endo-cleaving enzyme - low $\alpha_{e n z}$ values). Exocleaving enzymes released monomers or dimers, which caused a gradual decrease in the polymer length (Figure 2). Endo-cleaving enzymes efficiently shifted the polymer size distribution towards short lengths. Variations in the microbe uptake rate $u_{m i c}^{0}$ had no impact on the model sensitivity, i.e. with the chosen parameters, uptake was solely limited by the amount of available carbon in $\mathcal{D}_{u}$.

This simulation evidenced that C-STABILITY differentiates substrate transformation by enzyme and substrate uptake by decomposers, contrary to other models, which do not represent substrate polymerization and consider implicitly that both processes are simultaneous. This innovation enables to report the progressive modification of the decaying substrate by catabolism and how substrate availability to microbes uptake regulates the system dynamics.

\subsection{Effect of temporary substrate inaccessibility to enzyme on litter decompo- sition kinetics}

We ran a simulation of lignocellulose decomposition to illustrate how the spatial arrangement and interactions of biochemical moieties in a substrate can induce inaccessibility to enzyme. Indeed in wood, cellulose interaction with lignin makes it inaccessible to cellulases. Cellulose depolymerisation and utilisation can only start once the lignin barrier has been altered. This typically occurred during wood attack by woodrotting fungi producing lignolytic factors and cellulases, sometimes in a temporal sequence (Zhang et al. 
2016, 2019). In this second scenario, lignocellulose was made of $76 \%$ cellulose, $24 \%$ lignin. A specific design of the initial cellulose distribution was made to represent its embedment with lignin, which made it inaccessible to cellulolytic enzymes (Figure 4, see also the video in the Additional Information). Parameters were chosen to model a decomposition pattern, in general agreement with the findings of lignocellulose decomposition studies performed in microcosms (e.g. Kaffenberger and Schilling, 2015).

(a) Changes in polymerization distribution in the model pools.
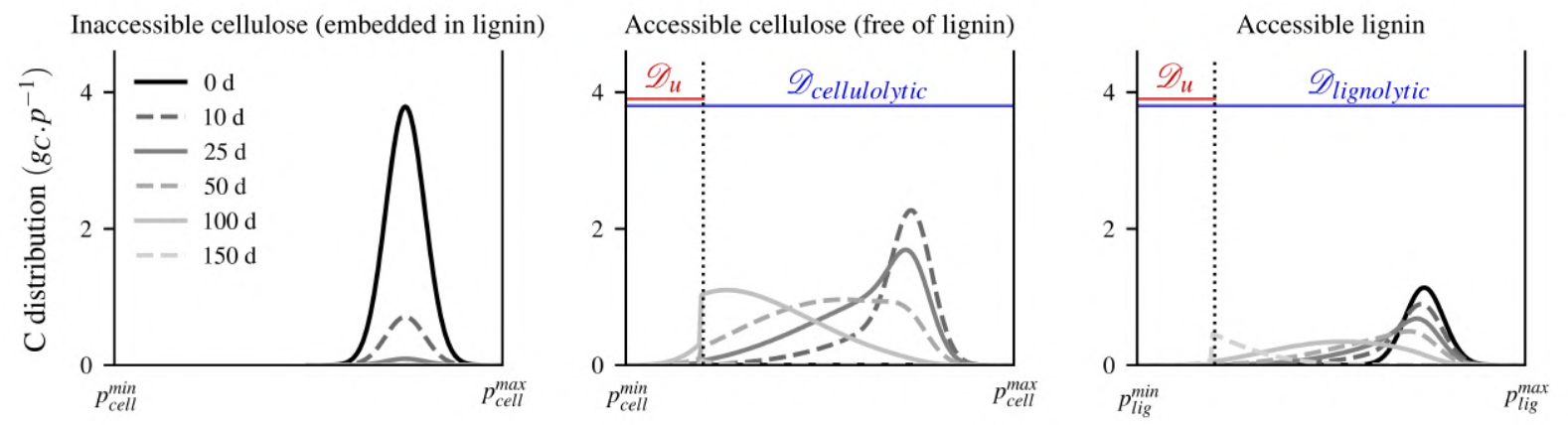

(b) Variations in C stocks over time in the model pools.

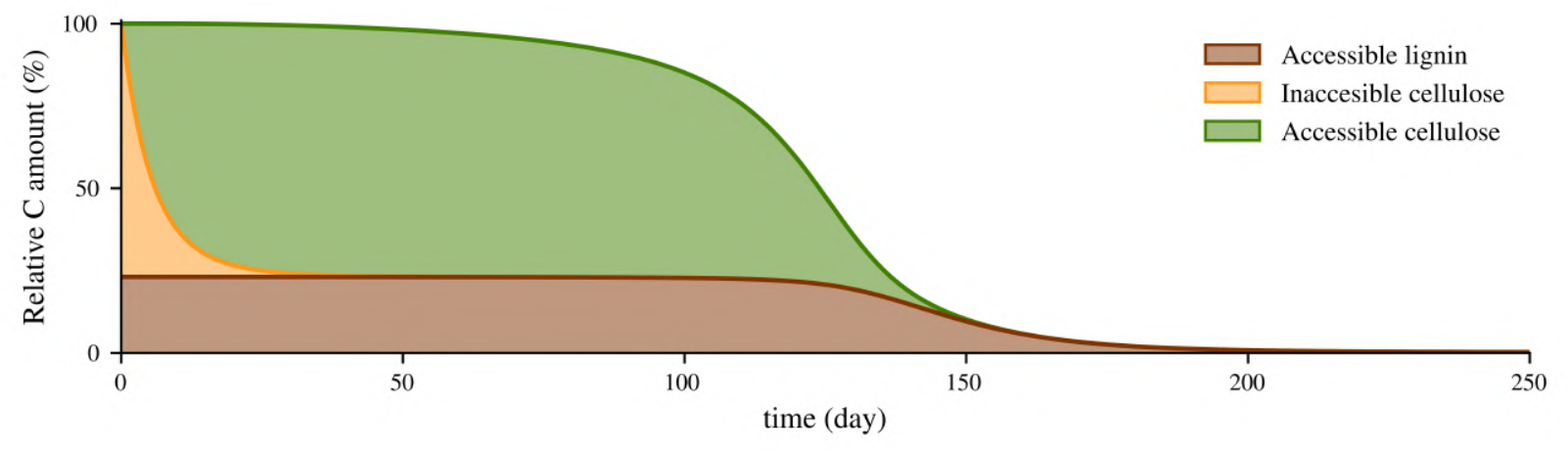

Figure 4: Degradation of lignocellulose by a microbe community producing cellulolytic and lignolytic enzymes (scenario 2). Cellulose is initially embedded in lignin and not accessible to its enzymes. The top panels (a) show the polymerization level in the pools of inaccessible cellulose, cellulose accessible to cellulolytic enzymes, lignin accessible to lignolytic enzymes. The polymerization axis is identical for both inaccessible and accessible cellulose. Domains of substrate accessibility to enzymes are in blue, domains of substrate accessibility to microbial uptake are in red. Bottom panel (b) shows the residual amount of $\mathrm{C}$ in the different pools.

Lignin deconstruction was initiated from the beginning of the simulation but the amount of lignin-C did not decrease prior to 120 days (Figure 4). Lignin depolymerization was very slow because of the combined effects of the low lignolytic rate $\tau_{e n z}^{0}$ and a high substrate cleavage factor $\alpha_{e n z}$ (supplementary table). Alteration of the lignin framework nevertheless rapidly opened the wood cell wall structure (Goodell et al. 2017) and 
cellulose became completely accessible to cellulolytic enzymes after 25 days. This required step for lignolysis delayed cellulose decomposition compared to the previous simulation with a pure cellulose substrate (95\% of the cellulose-C is consumed after 140 days versus 123 days in the previous case) - (Figure 4, video in the Additional Information).

Formally, mechanisms regulating substrate accessibility to enzymes were modeled in C-STABILITY with translation of the substrate chemistry distribution from a pool where the substrate was not accessible to another pool where it became accessible to its enzymes. The substrate remained unaltered as long as it was inaccessible to enzymes. This approach conceptually differs from that adopted in many compartment models where inaccessibility is reported by diminishing the substrate turnover rate compared to its free form (e.g. Parton et al. (1987); Moorhead and Sinsabaugh (2006); Stamati et al. (2013); Wieder et al. (2014)). In the scenario where cellulose was embedded in lignin, the translation was assumed to be a linear function of the lignolytic enzymes. The simulation of substrate desorption from a mineral surface or of the physical disruption of aggregates leading to the exposure of previously inaccessible OM could be performed by considering an instantaneous translation from the inaccessible to the accessible pool.

\subsection{Interactions between decomposer communities regulate the persistence of decomposing substrate and its chemistry}

The C-STABILITY framework is tailored specifically to reflect the succession of microbial players during litter decomposition and their biogeochemical functions. In a third scenario we implemented the model with two microbial functional communities, also called guilds, succeeding each other on a lignocellulose substrate. The two microbial guilds had the same biochemistry, consisting of lipids, proteins and sugars (supplementary table), but differed in their catabolic abilities. Recent studies showed that saprophitic fungi are the first to take action in wood decomposition. They were the main producers of enzymes involved in lignocellulose degradation. Bacteria or mycorrhizal fungi peak thereafter, breaking down and utilizing dead fungal biomass rather than plant polymers (Tláskal et al., 2016, Vorísková and Baldrian, 2013: Schneider et al., 2012, Lindahl and Tunlid, 2015). We referred to them as plant degraders and microbial residue degraders, respectively. In our simulation, the two communities also differed in their fitness. Microbial residue degraders were more competitive than plant degraders because of their higher carbon use efficiency and lower mortality rate (supplementary table). This succession is illustrated Figure 5a At the end of the simulation, there was almost no plant or microbial substrate left. Plant degraders dominated the microbial biomass during the 
(a) No-cheating
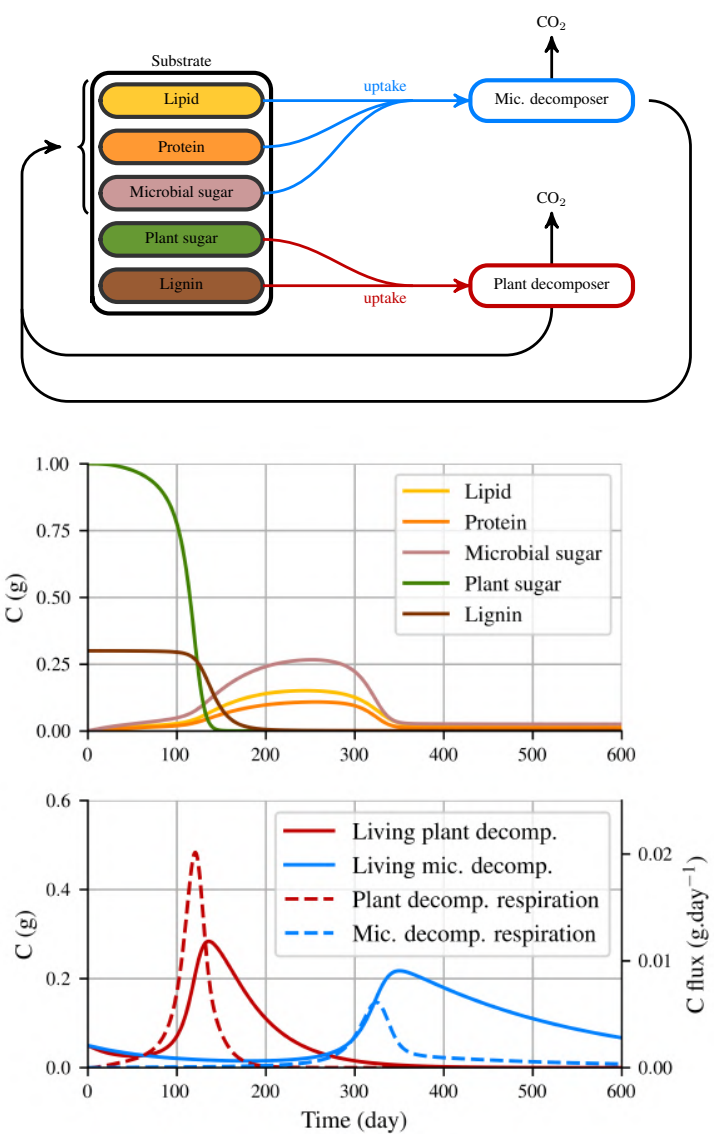

(b) Cheating
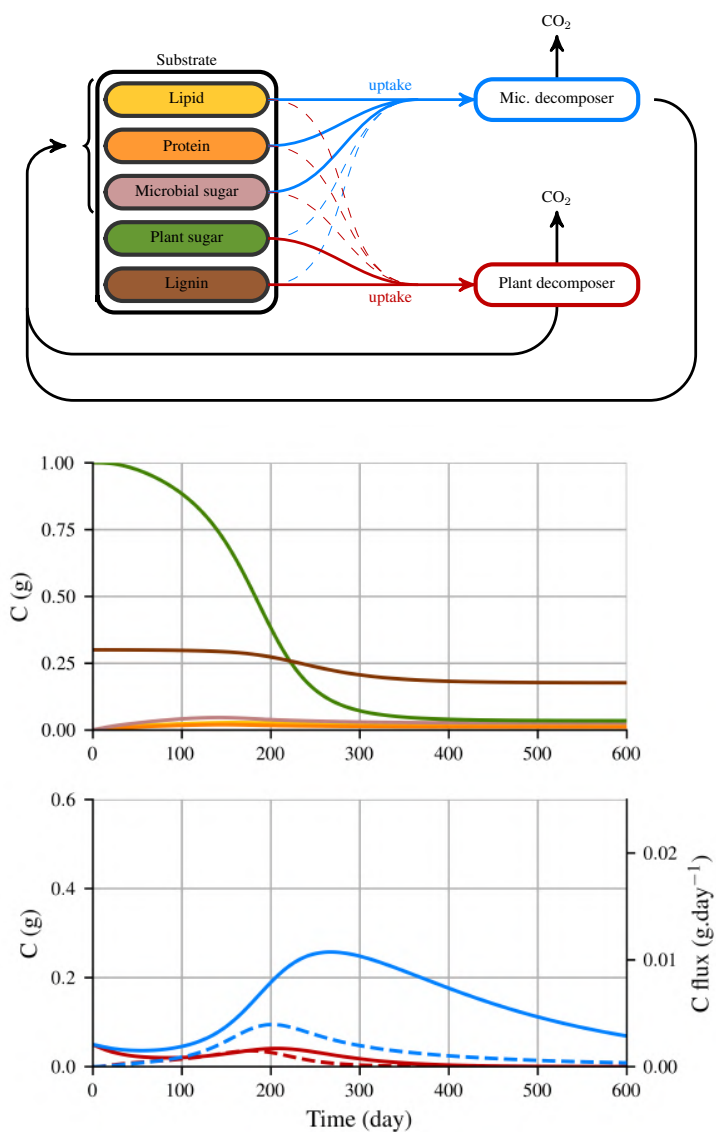

Figure 5: Effect of the succession of two decomposer communities on the residual substrate amount and biochemistry (scenario 3). The two communities have the same biochemical signature (50\% sugar, $30 \%$ lipid and $20 \%$ protein). Plant decomposers (red) produce cellulolytic and lignolytic enzymes. Microbial residues decomposers (Mic. decomposer - blue) produce enzymes that depolymerize lipids, proteins and microbial sugars. The two communities differ in their fitness. Microbial residue decomposers are more competitive than plant decomposers because of their higher carbon use efficiency and lower mortality rate (supplementary table). The effect of cheating behavior was tested as follows: (a) substrate uptake is only possible for the enzyme producer or (b) uptake is also possible for the cheater but at a lower rate than that of the enzyme producer.

first 260 days. The microbial residue degrader biomass slightly declined during this first stage. It started growing once the microbial residues were released upon the death of plant degraders, after around 200 days.

Despite the strategies implemented by decomposers to achieve privileged access to the substrate they depolymerize, e.g. antibiotics or secondary metabolites secretion (Hiscox and Boddy, 2017), Schneider et al. (2012) suggested that bacteria can also proliferate on simple carbohydrates provided by fungal enzymes. This has been referred to as cheating behavior. We simulated this behavior by changing the substrate uptake rate of the community that was not producing enzymes from zero to a positive value (supplementary table 
and figure). This change had direct impacts on the substrate residue chemistry at the end of the simulation. Indeed, when microbial residue degraders had an opportunity to opt for cheating behavior and benefit from the plant compounds fragmented by plant degraders, they developed faster than the plant degraders and rapidly dominated them (Figure 5b). The decline in fungal communities involved in plant depolymerization downregulated cellulose and lignin depolymerization and disappearance rates. Lignin-C therefore persisted at the end of the simulation (supplementary figure). Interactions between different functional decomposer communities thus seemed to be a strong driver of the residual substrate chemistry.

\subsection{Contributions of plant and microbe residues to SOM at steady-state}

Prediction of the contribution of microbial materials to the total carbon stock is of great interest for assessing the $\mathrm{C}$ sequestration potential of a system. Indeed microbial residues are currently considered as being the main precursors of stable OM (Cotrufo et al. 2015). For this purpose, we resolved the analytic formulation of the $\mathrm{C}$ stock and chemistry at steady-state Eqs. (13) to (15) while considering one microbial community, microbial residue recycling, continuous plant input and the substrate accessibility to enzymes (scenario 4).

A steady-state $\mathrm{C}$ stock of $1.553 \mathrm{~g}_{C} \cdot \mathrm{g}_{\text {soil }}^{-1}$ was computed with the parameters given in supplementary table. The living microbial biomass accounted for $8 \%$ of the total carbon stock [Eq. (13)], which was at the upper limit but within the range observed in soil across biomes (Fierer et al. 2009$)$. Cellulose and lignin were the most abundant chemical substances, each representing $33 \%$ of the $\mathrm{C}$ stock at steady state (Figure 6a). Microbial residues contributed to the remaining $33 \%$ as follows: $16 \%$ microbial sugar, $10 \%$ lipids and $7 \%$ proteins. Within each biochemical class, the substrate was a continuum of forms at different decomposition stages. In Figure 6a, the short peak on the right of the polymerization distribution of SOM corresponded to polymers initially entering the system as plant litter or microbial residues. OM altered by enzyme action was the main contributor of steady-state OM, as shown by the dominance of polymers with a lower degree of polymerization. There was no or almost no substrate in the $\mathcal{D}_{u}$ domains due to active microbial uptake of the smallest substrate fragments. The simulation closely reflected the SOM chemistry on the forest floor or in boreal soils observed in the field (Balaria and Johnson, 2013, Kohl et al., 2018). To predict the SOM chemistry in mineral soil horizons, C-STABILITY should account for the reduction in substrate accessibility due to interactions with the mineral phases, particularly for microbial products that are frequently involved in aggregates or bind on mineral surfaces (Miltner et al., 2012, Cotrufo et al., 2015, Clemmensen et al., 2013. Kallenbach et al. 2016; Wang et al., 2017).

The sensitivity analysis we carried out for the default parameters, in a system where substrates were 
(a) Representation of microbe necromass signature, plant input and SOM at steady state
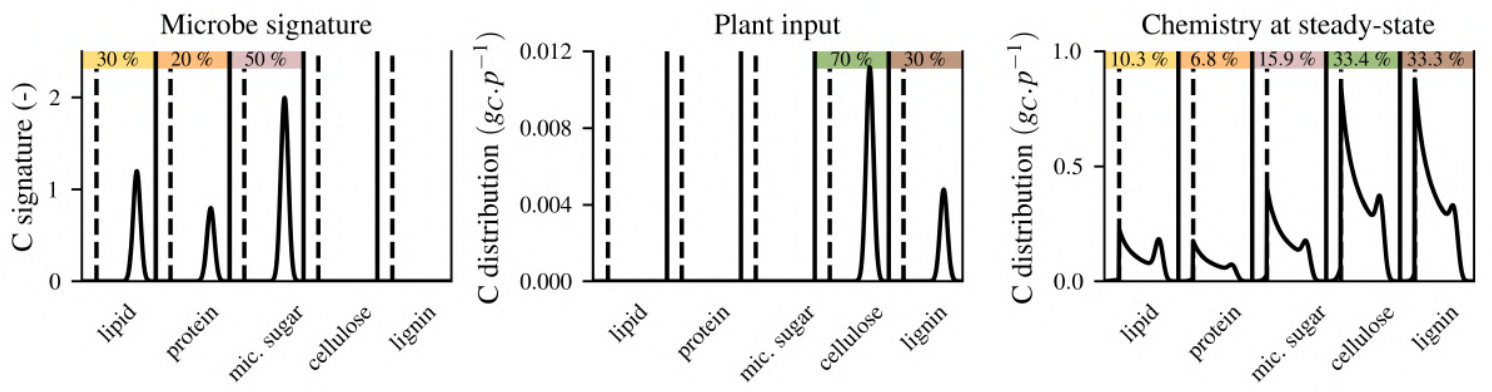

(b) Sensitivity analysis
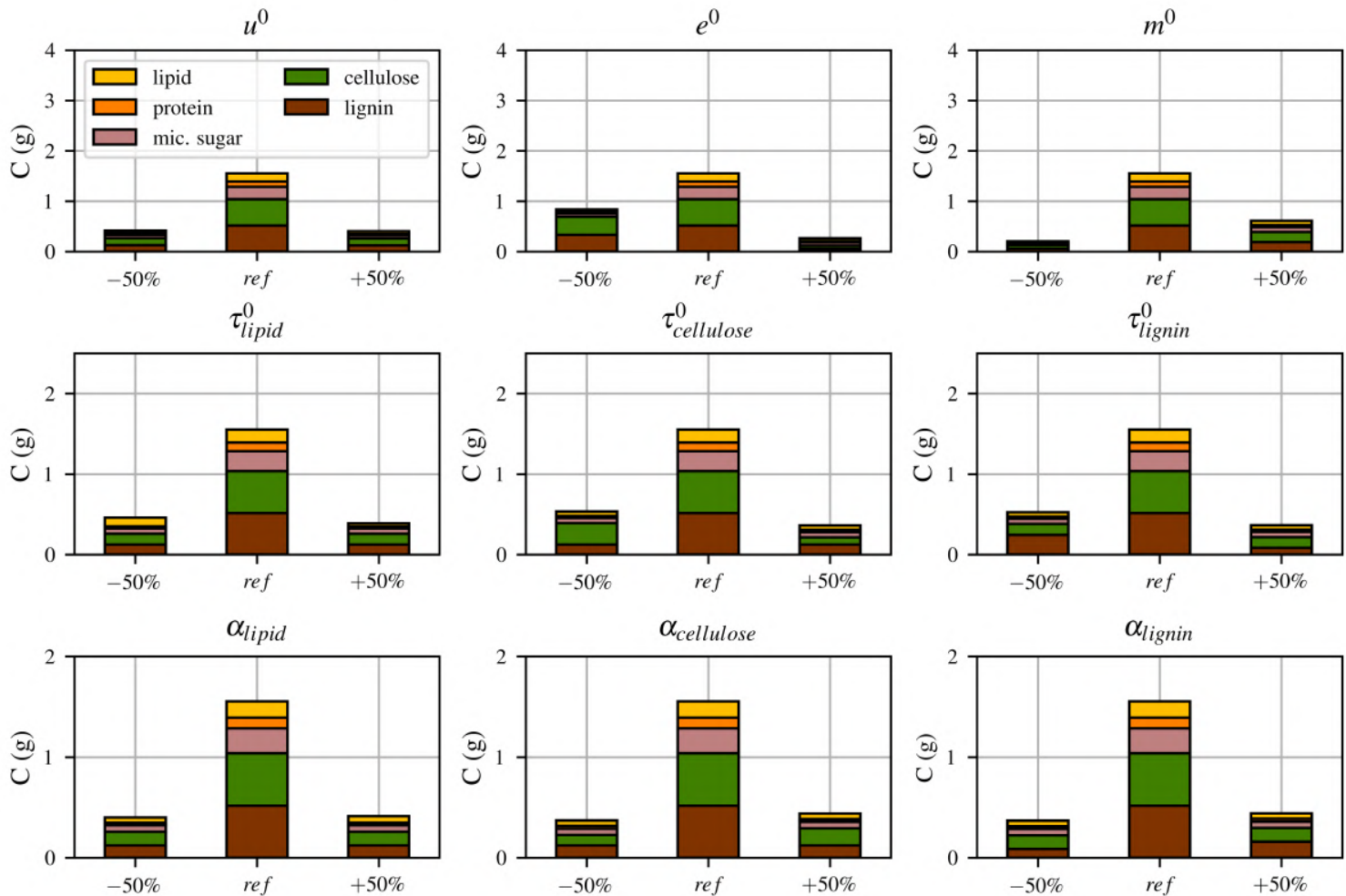

Figure 6: SOM at steady-state. (a) Representation of microbe necromass signature (biochemistry and level of polymerization), plant material input and the resulting SOM at steady state with parameter values given in supplementary table. All biochemical substrates are accessible. (b) Sensitivity analysis showing the change in total $\mathrm{C}$ stock and its distribution among biochemical classes with $\pm 50 \%$ changes in the parameters (variations in uptake rate $u_{m i c}^{0}$, carbon use efficiency $e_{m i c}^{0}$ and mortality rate $m_{m i c}^{0}$ at row 1 ; variations in enzyme action rate $\tau_{e n z}^{0}$ and cleavage factor $\alpha_{e n z}$ illustrated for lipid depolymerases, cellulolytic and lignolytic enzymes at rows 2 and 3 , respectively). Note that the scale of the $y$-axis varies.

accessible to their enzymes, confirmed the importance of microbial processes in controlling the amount and chemistry of SOM at steady-state (Figure 6b). As already reported (e.g. Liang et al., 2017), the carbon use 
efficiency parameter, $e_{m i c}^{0}$, which regulated the balance between $\mathrm{CO}_{2}$ production and metabolite production, was a major driver. An increase in $e_{m i c}^{0}$ raised the microbial biomass, which in turn accelerated the $\mathrm{C}$ turnover rate through increased depolymerization and respiration rates Eqs. (3), (11) and (12)]. This effect explained the decline in plant biochemical classes with increasing $e_{m i c}^{0}$. The biochemical classes of the microbial signature were not impacted by $e_{m i c}^{0}$. The accelerated SOM cycling induced by raising $e_{m i c}^{0}$ was indeed counterbalanced by a higher rate of microbial necromass input into the SOM pool Eqs. (14) and (15)].

The $\mathrm{C}$ stock also exhibited a strong positive linear dependence on the microbe mortality rate $m_{m i c}^{0}$, without any distinction among the various substrate biochemistries. In contrast, the $\mathrm{C}$ stock and distribution seemed to be quite insensitive to changes in the $u_{m i c}^{0}$ uptake rate for the range of tested values (Figure 6): $\mathrm{C}$ uptake was indeed limited here by the amount of accessible C. Consequently, the enzyme parameters controlling the availability of substrate for microbe uptake had a marked impact on the $\mathrm{C}$ stock and biochemistry (Figure 6b. An increase in the enzyme action rate $\tau_{e n z}^{0}$ decreased the quantity of its substrate at steadystate. In contrast, an increase in the $\alpha_{e n z}$ value increased the quantity of its substrate at steady-state. It corresponded to enhanced substrate exocleavage, which promoted the release of small fragments and preserved large polymers. These results contradicted the general belief that enzyme traits have a limited effect on SOM chemistry and quantity (Schimel and Schaeffer, 2012, Liang et al., 2017) and calls for closer consideration of the impact of catabolic processes on SOM cycling.

\section{Discussion}

C-STABILITY combines compartmental and continuous modelling approaches. This enables the representation of $\mathrm{OM}$ as a continuum of forms and the key processes governing its cycling, such as substrate accessibility and selective depolymerization, with a parsimonious number of parameters, which no models to date have been able to achieve. C-STABILITY breaks the abstract notion of quality of previous continuous models of SOM dynamics, which is closely associated with the recalcitrance concept and inadequate to account for several decomposers, and replaces it by an operational description of the OM chemistry in terms of biochemistry, polymerization and physicochemical inaccessibility. This major change allows to recognize that substrate access to enzymes and microbes strongly regulates OM turnover. Degradation is indeed not determined by any intrinsic molecular recalcitrance or specific decay rate as in many models. It is determined by the local environment properties, the substrate biochemistry and polymerization, and the functional diversity 
of microbes producing enzymes. Jointly, they regulate substrate accessibility to enzyme and its selective depolymerization prior uptake.

The two modelling philosophies inspiring C-STABILITY are usually opposed and have their own limitations for long term predictions. Weakness of the continuous approach is typical of the statistical modelling. Despite the strong predictive ability of statistical models for stable systems, the lack of explicit description of functional processes lower the confidence in predictions for perturbed systems. In opposite, compartment approach is descriptive and process-based. But, the more the system is complex, the more process-based approach is facing an explosion of its parameter number and uncertainty, making long term prediction hazardous. In C-STABILITY, SOM compartments and C fluxes are process-based inspired while the depolymerization process is depicted statistically as a continuous process. A complete process-based approach of OM depolymerization would be hazardous due to the multiplicity of chemical reactions to take into account and the scarcity of available data. Instead, the continuous distribution reports a wave of carbon traveling through the depolymerization process (Figure 21). The moment a polymer becomes accessible to enzymes, the carbon it contained begins to flow through less and less polymerized forms. This journey is parsimoniously described by the $\alpha_{e n z}$ parameter, which represents the substrate cleavage type (see Lebaz et al. (2015) for a similar approach).

C-STABILITY does not account for the immense variety of enzymes involved in SOM decomposition, nor for the very high diversity of microbial populations. Enzymes are grouped in families and microbes in functional guilds, both according to their action on SOM dynamics. Consequently only a few parameters are necessary to characterize a wide range of enzyme and microbial characteristics. This parsimony is crucial for the clarity and robustness of the model.

At this stage of the model development it is essential to verify, through simple cases, that the fundamental assumptions of the model are relevant and allow accurate description of observed processes. For this reason we set the model parameters at a constant value $\left(e_{m i c}^{0}, u_{m i c}^{0} \cdots\right)$ while we could assign a dependence on substrate polymerization properties or environmental conditions. There is, for example, strong experimental evidence that carbon use efficiency is dependent on the substrate biochemistry (Geyer et al., 2016). Nevertheless, through simple cases, we demonstrated that the C-STABILITY framework successfully represented the current understanding of OM cycling processes. The way forward is now to validate the model on datasets, first in controlled conditions. Further development of the model should then address the impact of environmental variables on microbe ecology and biogeochemical processes.

The model formalism has the advantage of offering extended possibilities for subsequent development stages. 
It is open to the introduction of competition relationships between decomposers and additional limiting factors such as water and nutrient availability. Besides, the equation describing $\mathrm{C}$ fluxes, such as the enzyme catalytic rate and microbe mortality, were chosen here to minimize the number of parameters. Yet other formulations could also be adopted. For example, the mortality rate formulation, which assumes linear dependence on the microbial biomass as in many microbial models, exhibits a decadal oscillatory behavior in response to $\mathrm{C}$ input perturbations, while demonstrating little or no sensitivity of steady-state $\mathrm{C}$ to changes in C input (Wang et al. 2014). To avoid this behavior, Georgiou et al. (2017) proposes a density-dependent formulation of mortality, which could be implemented in C-STABILITY. The enzyme catalytic rate could also be modulated by a saturating function such as the Michealis-Mentens equation Schimel and Weintraub, 2003), even though this was not required here to ensure model stability, as in earlier models.

Given the urgent societal demand to improve the prediction of carbon dynamics at the global scale, one great challenge in designing microbe models is to be able to effectively achieve micro- to global-upscaling (Wieder et al. 2015). It would be pointless to sum up enzyme and microbe activity predicted in an infinite number of heterogeneous environments considering the enormous computational resources that would be required. Alternatively, we postulate that the operational description of OM chemistry (biochemistry, physicochemical accessibility, polymerization) and functional decomposer guilds could be a means to effectively bridge the spatial scales. Such information is available from the subnanoscale to the plot scale through a range of techniques (spectroscopic techniques, chemical extractions, proteomics, metabar coding, etc.). This representation of OM could enable identification of key fine-scale processes and environmental factors, which emerge when describing OM dynamics at broader scales and are relevant for inclusion in Earth system models to improve their prediction accuracy.

\section{Methods}

\subsection{Substrate description}

The description of OM in C-STABILITY consists of several subdivisions. First, OM composing living organisms is separated from non-living organic substrate. Several living decomposers can be considered simultaneously (e.g. bacteria, fungi, etc.). Second, non-living OM from substrate is split into biochemical classes (cellulose or plant sugar, lignin, lipid, protein and microbial sugar in this study). Third, for each biochemical class, OM accessible to enzymatic activity is separated from OM which is inaccessible due to specific physicochemical conditions (e.g. interaction between different molecules, inclusion in aggregates, 
sorption on mineral surfaces, etc.). For each of these pools, a continuous description of the degree of OM polymerization $(p)$ is provided, as a distribution (Figure 1). For each biochemical class $*(*=$ cellulose, lignin, lipid, etc.), the range of the possible polymerization degree is identical for both inaccessible and accessible pools. The total amount of $\mathrm{C}\left(g_{C}\right)$ in each pool is

$$
C_{*}=\int_{p_{*}^{\min }}^{p_{*}^{\max }} \chi_{*}(p) d p
$$

where $p_{*}^{\min }$ and $p_{*}^{\max }$ are the maximum and minimum degrees of polymerization and $\chi_{*}\left(g_{C} \cdot p^{-1}\right)$ is the polymerization distribution. To differentiate substrate that is inaccessible from substrate accessible to enzymes, variables $\chi$ and $C$ are denoted $\chi_{*}^{i n}$ and $C_{*}^{i n}$, and $\chi_{*}^{a c}$ and $C_{*}^{a c}$, respectively. The polymerization axis is oriented from the lowest to the highest degree of polymerization (Figure 1b). A right-sided distribution corresponds to a highly polymerized substrate whereas a left-sided distribution corresponds to monomer or small oligomer forms.

Accessibility to microbe uptake is described by the interval (also called domain) $\mathcal{D}_{u}$, which corresponds to small OM compounds, monomers, dimers or trimers smaller than 600 Daltons (Lehmann and Kleber, 2015), that microbes are able to take up (in red in Figure 1b. Besides, accessibility to enzymes occurs in the $\mathcal{D}_{\text {enz }}$ domain (in blue in Figure 1b. Over time the substrate accessible to enzymes is depolymerized and its distribution shifts towards $\mathcal{D}_{u}$ and it eventually becomes accessible to microbe uptake.

The numerical rules chosen to represent polymerization are as simple as possible in the context of theoretical simulations. They could be modified for future applied studies. Each pool is associated with a polymerization interval $\left[p_{*}^{\min }, p_{*}^{\max }\right]$ of length two. Initial OM distributions are represented by Gaussian distributions centered at $\left.p_{*}^{\max }-0.5\right)$, with the standard deviation set at 0.1 . In the accessible pool, the microbial uptake domains $\mathcal{D}_{u}$ are positioned at the left of the interval with a relative length of $20 \%$, and enzymatic domains $\mathcal{D}_{\text {enz }}$ overlap the entire polymerization intervals.

\subsection{Substrate dynamics}

Three processes drive OM dynamics: (i) enzymatic activity, (ii) microbial biosynthesis, and (iii) changes in local physicochemical conditions. First, enzymes have a depolymerization role which enables transformation of highly polymerized substrate into fragments accessible to microbes. Second, microbial uptake of substrate is only possible for molecules having a very small degree of polymerization. When $\mathrm{C}$ is taken up, a fraction is respired and the remaining is metabolized, resulting in the biosynthesis of microbial molecules that return 
to the substrate upon microbe death. Each microbe has a specific signature that describes its composition in terms of biochemistry and polymerization. Third, changes in local OM conditions drive exchanges between $\mathrm{OM}$ accessible and non-accessible to enzymes (e.g. aggregate formation/break). All of these processes are considered on a daily basis $(d)$.

\subsubsection{Enzymatic activity}

Enzymes are specific to biochemical classes. They are not individually reported, but rather as a family of enzymes contributing to the depolymerization of a biochemical substrate (e.g. combined action of endoglucanase, exoglucanase, betaglucosidase, etc., on cellulose will be reported as cellulolytic action). The overall functioning of each enzyme family enz is described by two parameters: a depolymerization rate $\tau_{e n z}^{0}$ providing the number of broken bonds per time unit and a factor accounting for the type of substrate cleavage $\alpha_{e n z}$. The term $F_{e n z}^{a c t}\left(g_{C} \cdot p^{-1} \cdot d^{-1}\right)$ represents the change in polymerization of $\chi_{*}^{a c}$ due to enzyme activity for all $p \in \mathcal{D}_{\text {enz }}$,

$$
\begin{aligned}
F_{e n z}^{a c t}\left(\chi_{*}^{a c}, p, t\right)= & -\tau_{e n z}(t) \chi_{*}^{a c}(p, t) \\
& +\int_{\mathcal{D}_{\text {enz }}} \mathcal{K}_{e n z}\left(p, p^{\prime}\right) \tau_{e n z}(t) \chi_{*}^{a c}\left(p^{\prime}, t\right) d p^{\prime} .
\end{aligned}
$$

The depolymerization rate, $\tau_{e n z}\left(d^{-1}\right)$, is expressed as a linear function of microbial C biomass $C_{m i c}\left(g_{C}\right)$,

$$
\tau_{e n z}(t)=\tau_{e n z}^{0} C_{m i c}(t)
$$

where $\tau_{e n z}^{0}\left(g_{C}^{-1} \cdot d^{-1}\right)$ is the action rate of a given enzyme per amount of microbial C. If several microbial guilds are associated with the same enzyme family, we replace the $C_{m i c}$ term by a weighted sum of the $\mathrm{C}$ mass of all microbial guilds involved in Eq. (3) The $\mathcal{K}_{e n z}\left(p^{-1}\right)$ kernel provides the polymerization change from $p^{\prime}$ to $p$,

$$
\mathcal{K}_{e n z}\left(p, p^{\prime}\right)=1_{p \leq p^{\prime}}\left(\alpha_{e n z}+1\right) \frac{\left(p-p_{*}^{\text {min }}\right)^{\alpha_{e n z}}}{\left(p^{\prime}-p_{*}^{\text {min }}\right)^{\alpha_{e n z}+1}},
$$

where $1_{p \leq p^{\prime}}$ equals 1 if $p \leq p^{\prime}$ and 0 otherwise. The $\alpha_{e n z}$ cleavage factor denotes the enzyme efficiency to generate a large amount of small fragments and to shift the substrate distribution towards the microbe uptake domain $\mathcal{D}_{u}$ (Figure 22). $\alpha_{e n z}=1$ is typical of the action of endocleaving enzymes, which randomly disrupts any bond of its polymeric substrate and generates oligomers. The shift towards $\mathcal{D}_{u}$ is slower if $\alpha_{e n z}$ increases. 
This is characteristic of exocleaving enzymes, which attack the end-members of their polymeric substrate, generate small fragments and preserve highly polymerized compounds. To satisfy the mass balance, the kernel verifies $\int \mathcal{K}_{e n z}\left(p, p^{\prime}\right) d p=1$. Then $F_{\text {enz }}^{a c t}$ does not change the total $\mathrm{C}$ mass but only the polymerization distribution (i.e. $\int F_{e n z}^{a c t}(\chi, p, t) d p=0$ ).

\subsubsection{Microbial biosynthesis}

Each microbial group (denoted mic) produces new organic compounds with assimilated C. After death, the composition of the necromass returning to each biochemical pool $*$ of SOM is assumed to be constant, accessible and is depicted with a set of distributions $s_{m i c, *}$, named signature. Each distribution $s_{m i c, *}\left(p^{-1}\right)$ describes the polymerization of the dead microbial compounds returning to the pool $*$. The signature is normalized to ensure mass conservation, i.e. if we note that $S_{m i c, *}=\int_{p_{*}^{m i n}}^{p_{m}^{\max }} s_{m i c, *}(p) d p$, then we have $\sum_{*} S_{m i c, *}=1$.

For each accessible pool of substrate, the term $F_{m i c, *}^{u p t}$ describes how the microbes utilize the substrate available in the microbial uptake $\mathcal{D}_{u}$ domain (Figure 1b). For all $p \in \mathcal{D}_{u}$,

$$
F_{m i c, *}^{u p t}\left(\chi^{a c}, p, t\right)=u_{m i c, *}^{0} C_{m i c}(t) \chi_{*}^{a c}(p, t)
$$

where $u_{m i c, *}^{0}\left(g_{C}^{-1} \cdot d^{-1}\right)$ is the uptake rate per amount of microbe C. The substrate uptake rate linearly depends on the microbial C quantity.

Depending on a $\mathrm{C}$ use efficiency parameter $e_{m i c, *}^{0}$ (ratio between microbe assimilated $\mathrm{C}$ and taken up C), taken up $\mathrm{C}$ is respired or assimilated and biotransformed into microbial metabolites. This induces a change in the OM biochemistry and polymerization (Figure $1 \mathrm{a}$ ).

Finally microbial necromass returns to the substrate pools with a specific mortality, which linearly depends on the microbial C quantity,

$$
F_{m i c, *}^{n e c}(p, t)=m_{m i c}^{0} C_{m i c}(t) S_{m i c, *}(p),
$$

where $m_{m i c}^{0}\left(g_{C}^{-1} \cdot d^{-1}\right)$ is the mortality rate per amount of microbe C (Figure 1a).

\subsubsection{Change in local physicochemical conditions}

The distribution of a substrate inaccessible to its enzymes remains unchanged over time. A specific event changing the accessibility to enzymes (e.g. aggregate disruption or desorption from mineral surfaces) is 
modeled with a flux from the inaccessible to the accessible pool. Transfer between these pools is described by the $F_{a c, *}^{l o c}$ term for each biochemistry *,

$$
F_{a c, *}^{l o c}(p, t)=\tau_{t r}^{a c} \chi_{*}^{i n}(p, t)
$$

where $\tau_{t r, *}^{a c}\left(d^{-1}\right)$ is rate of local condition change toward accessibility.

Transfer in the opposite way (e.g. aggregate formation, association with mineral surfaces) is described by the $F_{i n, *}^{l o c}$ term,

$$
F_{i n, *}^{l o c}(p, t)=\tau_{t r}^{i n} \chi_{*}^{a c}(p, t)
$$

where $\tau_{t r, *}^{i n}\left(d^{-1}\right)$ is rate of local condition change toward inaccessibility.

\subsubsection{General equations}

The distribution dynamics for biochemical class $*$ is given by,

$$
\begin{aligned}
\frac{\partial \chi_{*}^{a c}}{\partial t}(p, t)= & \tau_{t r, *}^{a c} \chi_{*}^{i n}(p, t)-\tau_{t r, *}^{i n} \chi_{*}^{a c}(p, t) \\
& -\tau_{e n z}(t) \chi_{*}^{a c}(p, t) \\
& +\int_{\mathcal{D}_{e n z}} \mathcal{K}_{e n z}\left(p, p^{\prime}\right) \tau_{e n z}(t) \chi_{*}^{a c}\left(p^{\prime}, t\right) d p^{\prime} \\
& +\sum_{\text {mic }} C_{m i c}(t) m_{m i c}^{0} s_{m i c, *}(p) \\
& -1_{\mathcal{D}_{u}}(p) \sum_{\text {mic }} C_{m i c}(t) u_{m i c, *}^{0} \chi_{*}^{a c}(p, t) \\
\frac{\partial \chi_{*}^{i n}}{\partial t}(p, t)= & \tau_{t r, *}^{i n} \chi_{*}^{a c}(p, t)-\tau_{t r, *}^{a c} \chi_{*}^{i n}(p, t),
\end{aligned}
$$

where $1_{\mathcal{D}_{u}}(p)$ equals 1 if $p \in \mathcal{D}_{u}$ and 0 otherwise. The dynamics of microbial $C_{m i c}$ is obtained by,

$$
\begin{aligned}
\frac{d C_{m i c}}{d t}(t)= & -m_{m i c}^{0} C_{m i c}(t) \\
& +\sum_{*} u_{m i c, *}^{0} e_{m i c, *}^{0} C_{m i c}(t) \int_{\mathcal{D}_{u}} \chi_{*}^{a c}(p, t) d p,
\end{aligned}
$$


and the $\mathrm{CO}_{2}$ flux $\left(g_{C} \cdot d^{-1}\right)$ produced by the microbes is given by,

$$
F_{C O_{2}}(t)=C_{m i c}(t) \sum_{*} u_{m i c, *}^{0}\left(1-e_{m i c, *}^{0}\right) \int_{\mathcal{D}_{u}} \chi_{*}^{a c}(p, t) d p
$$

\subsubsection{Steady-state equations}

The formulation of the analytic expression for the steady-state requires several assumptions. First, we only consider accessible pools for all biochemical classes and one unique group of microbes. Second, we consider that $\mathrm{C}$ use efficiency and uptake parameters are identical for all biochemical classes. Third, we add a constant input term to equation 9 The input distribution is denoted $\iota_{*}\left(g_{C} \cdot p^{-1} \cdot d^{-1}\right)$ and the total carbon input flux is $I=\sum_{*} \int_{p_{*}^{m i n}}^{p_{*}^{\max }} \iota_{*}(p) d p\left(g_{C} \cdot d^{-1}\right)$.

At steady-state, the amount of microbial carbon is,

$$
C_{m i c}=\frac{e_{m i c}^{0} I}{\left(1-e_{m i c}^{0}\right) m_{m i c}^{0}} .
$$

For each biochemical class $*$, the steady-state distribution of $\mathrm{C}$ is obtained by combining two terms defined by the microbial uptake domain $\mathcal{D}_{u}=\left[p_{*}^{\min }, p_{*}^{u}\right]$ where $p_{*}^{u}=p_{*}^{\min }+0.4$. First, for $p \in\left[p_{*}^{u}, p_{*}^{\max }\right]$,

$$
\chi_{*}^{a c}(p)=\frac{\theta(p)}{\tau_{e n z}^{0}}+\frac{\alpha_{e n z}+1}{\tau_{e n z}^{0}\left(p-p_{*}^{\min }\right)} \int_{p}^{p_{*}^{\max }} \theta\left(p^{\prime}\right) d p^{\prime}
$$

and second, for $p \in\left[p_{*}^{\min }, p_{*}^{u}\right]$,

$$
\begin{aligned}
\chi_{*}^{a c}(p)= & \frac{\theta(p)}{\tau_{e n z}^{0}+u_{m i c}^{0}} \\
& -\frac{\alpha_{e n z}+1}{u_{m i c}^{0} 0.4^{1-\beta}} \int_{p_{*}^{m i n}}^{p_{*}^{u}} \theta(p) d p \\
& +\frac{\alpha_{e n z}+1}{\left(\tau_{e n z}^{0}+u_{m i c}^{0}\right) 0.4^{1-\beta}} \int_{p_{*}^{m i n}}^{p_{*}^{\max }} \theta(p) d p \\
& +\frac{\tau_{e n z}^{0}\left(\alpha_{e n z}+1\right)}{\left(\tau_{e n z}^{0}+u_{m i c}^{0}\right)^{2}} \int_{p}^{p_{*}^{u}} \frac{\left(p^{\prime}-p_{*}^{\text {min }}\right)^{\beta-1}}{\left(p-p_{*}^{\text {min }}\right)^{\beta}} \theta\left(p^{\prime}\right) d p^{\prime},
\end{aligned}
$$

where $\theta(p)=m_{m i c}^{0} s_{*}(p)+\frac{\iota_{*}(p)}{C_{m i c}}$ and $\beta=\frac{\tau_{e n z}^{0}-\alpha_{e n z} u^{0}}{\tau_{e n z}^{0}+u^{0}}$. 


\subsection{Scenarii}

\subsubsection{Scenario 1: Cellulose decomposition kinetics and model sensitivity}

A first simulation was run to depict cellulose depolymerisation and uptake by a decomposer community over one year (see parameters in supplementary table). We evaluated the model sensitivity to parameters using Sobol's sensitivity analysis (Sobol, 1993) (see Section 4.4). This was performed for a small parameter variation ( $\pm 5 \%$ uniform variability) using 12000 model simulations.

\subsubsection{Scenario 2: Effect of substrate inaccessibility to enzyme on litter decomposition kinetics}

A simulation of lignocellulose (76\% cellulose, $24 \%$ lignin) degradation was performed by taking into account peroxidases, which deconstruct the lignin polymer, and cellulases, which hydrolyse cellulose.

The cellulose was initially embedded in lignin and inaccessible to cellulase. Progressive transfer to the accessible pool was linearly related to the activity of lignolytic enzymes in Eq. (7)

$$
\tau_{\text {tr,cell. }}^{a c}=\tau_{\text {tr }, \text { cell. }}^{a c, 0} \int_{\mathcal{D}_{\text {lig. }}} \tau_{\text {lig. }}^{0} C_{m i c}(t) \chi_{\text {lig. }}^{a c}(p, t) d p
$$

where $\mathcal{D}_{\text {lig. }}$ is the domain of lignolytic activity and where the $\tau_{t r, c e l l}^{a c, 0}$. coefficient is set at $13 g_{C}^{-1}$ for the current illustration.

The simulation was performed over one year. Enzymatic and microbial parameters given in supplementary table were chosen to be closely in line with the litter decomposition and enzyme action observation of Kaffenberger and Schilling (2015), Lashermes et al. (2016) and Zhang et al. (2016).

\subsubsection{Scenario 3: Effect of community succession on $\mathrm{C}$ fluxes and substrate biochemistry}

We simulated the succession of two microbial functional communities, or guilds, on the previous lignocellulose, considering microbial residue recycling. The parameters (supplementary table) were chosen according to the microbial community succession observations of Snajdr et al. (2011), Schneider et al. (2012) and Tláskal et al. (2016). The first microbial community was specialized in plant substrate degradation, the second was specialized in the degradation of microbial residues. We referred to them as plant degraders and microbial residue degraders. Microbial residue degraders were more competitive than plant degraders because of their higher carbon use efficiency and lower mortality rate (supplementary table). Both communities had the same biochemical signature, i.e. $50 \%$ polysaccharides, $30 \%$ lipids and $20 \%$ proteins. We tested the impact of cheating as follows. Either uptake was impossible, i.e. $u_{0}$ equaled 0 for the community not involved 
in enzyme production, or uptake was possible but at a lower rate than the enzyme producers because the substrate fragments were released in the vicinity of the enzyme producers (supplementary table).

\subsubsection{Scenario 4: SOM composition at steady state.}

We resolved the analytic formulation of the $\mathrm{C}$ stock and chemistry at steady-state by considering one microbial community, continuous plant input at a rate of $4 \mathrm{mg}_{C} \cdot \mathrm{g}_{\text {soil }}{ }^{-1}$ day ${ }^{-1}$ (Wang et al., 2012) and microbial recycling Eqs. (13) to (15)]. To be able to specifically calculate the steady-state, cellulose substrate was not embedded in lignin but directly accessible to cellulolytic enzymes (Figure 6). Compared to previous scenarii related to laboratory experiments, enzymatic activities were divided by five to account for the impact of in-situ climatic conditions (Balaria and Johnson, 2013). Other enzymatic and microbial parameters are given in supplementary table. To explore how the catabolic traits of enzymes and anabolic traits of microbes affect the SOM composition, we modified individual parameters by $50 \%$ and documented their effects on the steady-state amount of $\mathrm{C}$ and its biochemical signature.

\subsection{Sensitivity analysis}

Sensitivity analysis encompasses a wide range of methods aimed at determining how the uncertainty of model parameters influences the model outputs. These methods improve the understanding of the model and its design.

We considered a specific method for calculating sensitivity indices defined by Sobol (1993). The method was designed to decompose the variance of a model output, denoted $y$, according to the various degrees of interaction between the $n$ uncertain parameters $\left(x_{i}\right)_{i \in\{1, n\}}$. Formally, by assuming that the parameter uncertainties are independent, the model output could be expressed as a sum of functions that take parameter interactions into account,

$$
y=f_{0}+\sum_{i=1}^{n} f_{i}\left(x_{i}\right)+\sum_{\substack{i, j=1 \\ i \neq j}}^{n} f_{i, j}\left(x_{i}, x_{j}\right)+\ldots+f_{1, \ldots, n}\left(x_{1}, \ldots, x_{n}\right) .
$$

This formulation leads to the definition of several sensitivity indices. The first-order Sobol's index of each parameter is,

$$
S_{i}=\frac{\operatorname{Var}\left(f_{i}\left(x_{i}\right)\right)}{\operatorname{Var}(y)}
$$


and higher order indices are defined by $S_{i, j}=\operatorname{Var}\left(f_{i, j}\left(x_{i}, x_{j}\right)\right) / \operatorname{Var}(y)$, and so on. These indices are unique, with a value of 0 to 1 and their sum equals 1 .

Here we focused on the first-order indices, which are used to an increasing extent in ecological modeling (Cariboni et al., 2007, Sainte-Marie and Cournède, 2019) as they are usually sufficient to give a straightforward interpretation of the actual influence of different parameters. Sobol's indices were estimated using a Monte Carlo estimator of the variance (Cournède et al., 2013).

\subsection{Implementation}

The model was implemented in the Julia ${ }^{\circledR}$ language (Bezanson et al., 2012). An explicit finite difference scheme approximates the solutions of integro-differential equations with a $\Delta t=0.1 d$. time step and a $\Delta p=0.01$ polymerization step. Differential equations were solved with a Runge-Kutta method.

\section{Code availability}

The code is available at: https://github.com/juliensaintemarie/C-STABILITY

\section{References}

Abramoff, R., Xu, X., Hartman, M., O’Brien, S., Feng, W., Davidson, E., Finzi, A., Moorhead, D., Schimel, J., Torn, M., and Mayes, M. A. (2018). The millennial model: in search of measurable pools and transformations for modeling soil carbon in the new century. Biogeochemistry, 137(1-2):51-71.

Ågren, G., Barrandon, M., Saint-André, L., and Sainte-Marie, J. (2017). Analysis of integro-differential equations modeling the vertical decomposition of soil organic matter. Quarterly of Applied Mathematics, 75(1):131-153.

Ågren, G. I., Kleja, D. B., and Bosatta, E. (2018). Modelling dissolved organic carbon production in coniferous forest soils. Soil Science Society of America Journal.

Allison, S. D. (2012). A trait-based approach for modelling microbial litter decomposition. Ecology Letters, 15(9):1058-1070. 
Balaria, A. and Johnson, C. E. (2013). Compositional characterization of soil organic matter and hot-waterextractable organic matter in organic horizons using a molecular mixing model. Journal of Soils and Sediments, 13(6):1032-1042.

Bartsev, S. I. and Pochekutov, A. A. (2019). An elementary multistage discrete model of soil organic matter transformations with a continuous scale of stability. Ecological Modelling, 393:61-65.

Bezanson, J., Karpinski, S., Shah, V. B., and Edelman, A. (2012). Julia: A fast dynamic language for technical computing.

Blankinship, J. C., Berhe, A. A., Crow, S. E., Druhan, J. L., Heckman, K. A., Keiluweit, M., Lawrence, C. R., Marín-Spiotta, E., Plante, A. F., Rasmussen, C., et al. (2018). Improving understanding of soil organic matter dynamics by triangulating theories, measurements, and models. Biogeochemistry, 140(1):1-13.

Cariboni, J., Gatelli, D., Liska, R., and Saltelli, A. (2007). The role of sensitivity analysis in ecological modelling. Ecological Modelling, 203(1-2):167 - 182. Special Issue on Ecological Informatics: BiologicallyInspired Machine Learning 4th Conference of the International Society for Ecological Informatics.

Clemmensen, K. E., Bahr, A., Ovaskainen, O., Dahlberg, A., Ekblad, A., Wallander, H., Stenlid, J., Finlay, R. D., Wardle, D. A., and Lindahl, B. D. (2013). Roots and associated fungi drive long-term carbon sequestration in boreal forest. Science, 339(6127):1615-1618.

Cotrufo, M. F., Soong, J. L., Horton, A. J., Campbell, E. E., Haddix, M. L., Wall, D. H., and Parton, A. J. (2015). Formation of soil organic matter via biochemical and physical pathways of litter mass loss. Nature GeoScience, 8(10):776+.

Cournède, P.-H., Chen, Y., Wu, Q., Baey, C., and Bayol, B. (2013). Development and evaluation of plant growth models : Methodology and implementation in the pygmalion platform. Mathematical Modelling of Natural Phenomena, 8(4):112-130.

Dungait, J. A., Hopkins, D. W., Gregory, A. S., and Whitmore, A. P. (2012). Soil organic matter turnover is governed by accessibility not recalcitrance. Global Change Biology, 18(6):1781-1796.

Eastwood, D. C., Floudas, D., Binder, M., Majcherczyk, A., Schneider, P., Aerts, A., Asiegbu, F. O., Baker, S. E., Barry, K., Bendiksby, M., Blumentritt, M., Coutinho, P. M., Cullen, D., de Vries, R. P., Gathman, A., Goodell, B., Henrissat, B., Ihrmark, K., Kauserud, H., Kohler, A., LaButti, K., Lapidus, A., Lavin, 
J. L., Lee, Y.-H., Lindquist, E., Lilly, W., Lucas, S., Morin, E., Murat, C., Oguiza, J. A., Park, J., Pisabarro, A. G., Riley, R., Rosling, A., Salamov, A., Schmidt, O., Schmutz, J., Skrede, I., Stenlid, J., Wiebenga, A., Xie, X., Kuees, U., Hibbett, D. S., Hoffmeister, D., Hogberg, N., Martin, F., Grigoriev, I. V., and Watkinson, S. C. (2011). The plant cell wall-decomposing machinery underlies the functional diversity of forest fungi. Science, 333(6043):762-765.

Fierer, N., Strickland, M. S., Liptzin, D., Bradford, M. A., and Cleveland, C. C. (2009). Global patterns in belowground communities. Ecology Letters, 12(11):1238-1249.

Floudas, D., Binder, M., Riley, R., Barry, K., Blanchette, R. A., Henrissat, B., Martinez, A. T., Otillar, R., Spatafora, J. W., Yadav, J. S., Aerts, A., Benoit, I., Boyd, A., Carlson, A., Copeland, A., Coutinho, P. M., de Vries, R. P., Ferreira, P., Findley, K., Foster, B., Gaskell, J., Glotzer, D., Gorecki, P., Heitman, J., Hesse, C., Hori, C., Igarashi, K., Jurgens, J. A., Kallen, N., Kersten, P., Kohler, A., Kuees, U., Kumar, T. K. A., Kuo, A., LaButti, K., Larrondo, L. F., Lindquist, E., Ling, A., Lombard, V., Lucas, S., Lundell, T., Martin, R., McLaughlin, D. J., Morgenstern, I., Morin, E., Murat, C., Nagy, L. G., Nolan, M., Ohm, R. A., Patyshakuliyeva, A., Rokas, A., Ruiz-Duenas, F. J., Sabat, G., Salamov, A., Samejima, M., Schmutz, J., Slot, J. C., John, F. S., Stenlid, J., Sun, H., Sun, S., Syed, K., Tsang, A., Wiebenga, A., Young, D., Pisabarro, A., Eastwood, D. C., Martin, F., Cullen, D., Grigoriev, I. V., and Hibbett, D. S. (2012). The paleozoic origin of enzymatic lignin decomposition reconstructed from 31 fungal genomes. Science, 336(6089):1715-1719.

Georgiou, K., Abramoff, R. Z., Harte, J., Riley, W. J., and Torn, M. S. (2017). Microbial community-level regulation explains soil carbon responses to long-term litter manipulations. Nature Communications, 8.

Geyer, K. M., Kyker-Snowman, E., Grandy, A. S., and Frey, S. D. (2016). Microbial carbon use efficiency: accounting for population, community, and ecosystem-scale controls over the fate of metabolized organic matter. Biogeochemistry, 127(2-3):173-188.

Goodell, B., Zhu, Y., Kim, S., Kafle, K., Eastwood, D., Daniel, G., Jellison, J., Yoshida, M., Groom, L., Pingali, S. V., and O'Neill, H. (2017). Modification of the nanostructure of lignocellulose cell walls via a non-enzymatic lignocellulose deconstruction system in brown rot wood-decay fungi. Biotechnology for Biofuels, 10.

Hiscox, J. and Boddy, L. (2017). Armed and dangerous-chemical warfare in wood decay communities. Fungal Biology Reviews, 31(4):169-184. 
Kaffenberger, J. T. and Schilling, J. S. (2015). Comparing lignocellulose physiochemistry after decomposition by brown rot fungi with distinct evolutionary origins. Environmental Microbiology, 17(12):4885-4897.

Kaiser, C., Franklin, O., Richter, A., and Dieckmann, U. (2015). Social dynamics within decomposer communities lead to nitrogen retention and organic matter build-up in soils. Nature communications, 6 .

Kallenbach, C. M., Frey, S. D., and Grandy, A. S. (2016). Direct evidence for microbial-derived soil organic matter formation and its ecophysiological controls. Nature Communications, 7.

Kemmitt, S. J., Lanyon, C. V., Waite, I. S., Wen, Q., Addiscott, T. M., Bird, N. R. A., O'Donnell, A. G., and Brookes, P. (2008). Mineralization of native soil organic matter is not regulated by the size, activity or composition of the soil microbial biomass - a new perspective. Soil Biology \& Biochemistry, 40(1):61-73.

Kohl, L., Philben, M., Edwards, K. A., Podrebarac, F. A., Warren, J., and Ziegler, S. E. (2018). The origin of soil organic matter controls its composition and bioreactivity across a mesic boreal forest latitudinal gradient. Global Change Biology, 24(2):E458-E473.

Kohler, A., Kuo, A., Nagy, L. G., Morin, E., Barry, K. W., Buscot, F., Canback, B., Choi, C., Cichocki, N., Clum, A., Colpaert, J., Copeland, A., Costa, M. D., Dore, J., Floudas, D., Gay, G., Girlanda, M., Henrissat, B., Herrmann, S., Hess, J., Hogberg, N., Johansson, T., Khouja, H.-R., LaButti, K., Lahrmann, U., Levasseur, A., Lindquist, E. A., Lipzen, A., Marmeisse, R., Martino, E., Murat, C., Ngan, C. Y., Nehls, U., Plett, J. M., Pringle, A., Ohm, R. A., Perotto, S., Peter, M., Riley, R., Rineau, F., Ruytinx, J., Salamov, A., Shah, F., Sun, H., Tarkka, M., Tritt, A., Veneault-Fourrey, C., Zuccaro, A., Tunlid, A., Grigoriev, I. V., Hibbett, D. S., Martin, F., and Co, M. G. I. (2015). Convergent losses of decay mechanisms and rapid turnover of symbiosis genes in mycorrhizal mutualists. Nature Genetics, 47(4):410-U176.

Lashermes, G., Gainvors-Claisse, A., Recous, S., and Bertrand, I. (2016). Enzymatic strategies and carbon use efficiency of a litter-decomposing fungus grown on maize leaves, stems, and roots. Frontiers in Microbiology, 7.

Lebaz, N., Cockx, A., Spérandio, M., and Morchain, J. (2015). Population balance approach for the modelling of enzymatic hydrolysis of cellulose. The Canadian Journal of Chemical Engineering, 93(2):276-284.

Lehmann, J. and Kleber, M. (2015). The contentious nature of soil organic matter. Nature, 528(7580):60-68.

Liang, C., Amelung, W., Lehmann, J., and Kästner, M. (2019). Quantitative assessment of microbial necromass contribution to soil organic matter. Global Change Biology. 
Liang, C., Schimel, J. P., and Jastrow, J. D. (2017). The importance of anabolism in microbial control over soil carbon storage. Nature Microbiology, 2(8).

Lindahl, B. D. and Tunlid, A. (2015). Ectomycorrhizal fungi-potential organic matter decomposers, yet not saprotrophs. New Phytologist, 205(4):1443-1447.

Menichetti, L., Ågren, G. I., Barré, P., Moyano, F., and Kätterer, T. (2019). Generic parameters of firstorder kinetics accurately describe soil organic matter decay in bare fallow soils over a wide edaphic and climatic range. Scientific Reports, 9(1):1-12.

Miltner, A., Bombach, P., Schmidt-Bruecken, B., and Kaestner, M. (2012). Som genesis: microbial biomass as a significant source. Biogeochemistry, 111(1-3):41-55.

Monga, O., Garnier, P., Pot, V., Coucheney, E., Nunan, N., Otten, W., and Chenu, C. (2014). Simulating microbial degradation of organic matter in a simple porous system using the 3-d diffusion-based model mosaic. Biogeosciences, 11(8):2201-2209.

Moorhead, D. and Sinsabaugh, R. (2006). A theoretical model of litter decay and microbial interaction. Ecological Monographs, 76(2):151-174.

Nagy, L. G., Riley, R., Bergmann, P. J., Krizsán, K., Martin, F. M., Grigoriev, I. V., Cullen, D., and Hibbett, D. S. (2016). Genetic bases of fungal white rot wood decay predicted by phylogenomic analysis of correlated gene-phenotype evolution. Molecular Biology and Evolution, 34(1):35-44.

Parton, W., Schimel, D., Cole, C., and Ojima, D. (1987). Analysis of factor controlling soil organic-matter levels in great-plains grasslands. Soil Science Society of America Journal, 51(5):1173-1179.

Riley, R., Salamov, A. A., Brown, D. W., Nagy, L. G., Floudas, D., Held, B. W., Levasseur, A., Lombard, V., Morin, E., Otillar, R., Lindquist, E. A., Sun, H., LaButti, K. M., Schmutz, J., Jabbour, D., Luo, H., Baker, S. E., Pisabarro, A. G., Walton, J. D., Blanchette, R. A., Henrissat, B., Martin, F., Cullen, D., Hibbett, D. S., and Grigoriev, I. V. (2014). Extensive sampling of basidiomycete genomes demonstrates inadequacy of the white-rot/brown-rot paradigm for wood decay fungi. Proceedings of the National Academy of Sciences of the United States of America, 111(27):9923-9928.

Rowley, M. C., Grand, S., and Verrecchia, É. P. (2018). Calcium-mediated stabilisation of soil organic carbon. Biogeochemistry, 137(1-2):27-49. 
Sainte-Marie, J. and Cournède, P.-H. (2019). Insights of global gensitivity analysis in biological models with dependent parameters. Journal of Agricultural Biological and Environmental Statistics, 24(1):92-111.

Schimel, J. P. and Schaeffer, S. M. (2012). Microbial control over carbon cycling in soil. Frontiers in Microbiology, 3 .

Schimel, J. P. and Weintraub, M. N. (2003). The implications of exoenzyme activity on microbial carbon and nitrogen limitation in soil: a theoretical model. Soil Biology and Biochemistry, 35(4):549-563.

Schmidt, M. W., Torn, M. S., Abiven, S., Dittmar, T., Guggenberger, G., Janssens, I. A., Kleber, M., Kögel-Knabner, I., Lehmann, J., Manning, D. A., et al. (2011). Persistence of soil organic matter as an ecosystem property. Nature, 478(7367):49.

Schneider, T., Keiblinger, K. M., Schmid, E., Sterflinger-Gleixner, K., Ellersdorfer, G., Roschitzki, B., Richter, A., Eberl, L., Zechmeister-Boltenstern, S., and Riedel, K. (2012). Who is who in litter decomposition? metaproteomics reveals major microbial players and their biogeochemical functions. Isme Journal, 6(9):1749-1762.

Shi, Z., Crowell, S., Luo, Y., and Moore, B. (2018). Model structures amplify uncertainty in predicted soil carbon responses to climate change. Nature Communications, 9(1):2171.

Skyba, O., Douglas, C. J., and Mansfield, S. D. (2013). Syringyl-rich lignin renders poplars more resistant to degradation by wood decay fungi. Applied and Environmental Microbiology, 79(8):2560-2571.

Snajdr, J., Cajthaml, T., Valaskova, V., Merhautova, V., Petrankova, M., Spetz, P., Leppanen, K., and Baldrian, P. (2011). Transformation of quercus petraea litter: successive changes in litter chemistry are reflected in differential enzyme activity and changes in the microbial community composition. Fems Microbiology Ecology, 75(2):291-303.

Sobol, I. (1993). Sensitivity analysis for non-linear mathematical models. Mathematical Modeling and Computational Experiment, pages 407-414.

Stamati, F. E., Nikolaidis, N. P., Banwart, S., and Blum, W. E. (2013). A coupled carbon, aggregation, and structure turnover (cast) model for topsoils. Geoderma, 211:51-64.

Sulman, B. N., Moore, J. A., Abramoff, R., Averill, C., Kivlin, S., Georgiou, K., Sridhar, B., Hartman, M. D., Wang, G., Wieder, W. R., et al. (2018). Multiple models and experiments underscore large uncertainty in soil carbon dynamics. Biogeochemistry, 141(2):109-123. 
Talbot, J. M., Martin, F., Kohler, A., Henrissat, B., and Peay, K. G. (2015). Functional guild classification predicts the enzymatic role of fungi in litter and soil biogeochemistry. Soil Biology and Biochemistry, $88: 441-456$.

Tláskal, V., Vorísková, J., and Baldrian, P. (2016). Bacterial succession on decomposing leaf litter exhibits a specific occurrence pattern of cellulolytic taxa and potential decomposers of fungal mycelia. Fems Microbiology Ecology, 92(11).

Todd-Brown, K. E. O., Hopkins, F. M., Kivlin, S. N., Talbot, J. M., and Allison, S. D. (2012). A framework for representing microbial decomposition in coupled climate models. Biogeochemistry, 109(1-3):19-33.

Treseder, K. K., Balser, T. C., Bradford, M. A., Brodie, E. L., Dubinsky, E. A., Eviner, V. T., Hofmockel, K. S., Lennon, J. T., Levine, U. Y., MacGregor, B. J., Pett-Ridge, J., and Waldrop, M. P. (2012). Integrating microbial ecology into ecosystem models: challenges and priorities. Biogeochemistry, 109(13):7-18.

Vogel, L. E., Makowski, D., Garnier, P., Vieuble-Gonod, L., Coquet, Y., Raynaud, X., Nunan, N., Chenu, C., Falconer, R., and Pot, V. (2015). Modeling the effect of soil meso- and macropores topology on the biodegradation of a soluble carbon substrate. Advances in Water Resources, 83:123-136.

Vorísková, J. and Baldrian, P. (2013). Fungal community on decomposing leaf litter undergoes rapid successional changes. Isme Journal, 7(3):477-486.

Wang, G., Post, W. M., Mayes, M. A., Frerichs, J. T., and Sindhu, J. (2012). Parameter estimation for models of ligninolytic and cellulolytic enzyme kinetics. Soil Biology \& Biochemistry, 48:28-38.

Wang, T., Tian, Z., Bengtson, P., Tunlid, A., and Persson, P. (2017). Mineral surface-reactive metabolites secreted during fungal decomposition contribute to the formation of soil organic matter. Environmental Microbiology, 19(12):5117-5129.

Wang, Y. P., Chen, B. C., Wieder, W. R., Leite, M., Medlyn, B. E., Rasmussen, M., Smith, M. J., Agusto, F. B., Hoffman, F., and Luo, Y. Q. (2014). Oscillatory behavior of two nonlinear microbial models of soil carbon decomposition. Biogeosciences, 11(7):1817-1831.

Wieder, W. R., Allison, S. D., Davidson, E. A., Georgiou, K., Hararuk, O., He, Y., Hopkins, F., Luo, Y., Smith, M. J., Sulman, B., Todd-Brown, K., Wang, Y.-P., Xia, J., and Xu, X. (2015). Explicitly representing soil microbial processes in earth system models. Global Biogeochemical Cycles, 29(10):1782-1800. 
Wieder, W. R., Grandy, A. S., Kallenbach, C. M., and Bonan, G. B. (2014). Integrating microbial physiology and physio-chemical principles in soils with the microbial-mineral carbon stabilization (mimics) model. Biogeosciences, 11(14):3899-3917.

Zhang, J., Presley, G. N., Hammel, K. E., Ryu, J.-S., Menke, J. R., Figueroa, M., Hu, D., Orr, G., and Schilling, J. S. (2016). Localizing gene regulation reveals a staggered wood decay mechanism for the brown rot fungus postia placenta. Proceedings of the National Academy of Sciences of the United States of America, 113(39):10968-10973.

Zhang, J., Silverstein, K. A., Castaño, J. D., Figueroa, M., and Schilling, J. S. (2019). Gene regulation shifts shed light on fungal adaption in plant biomass decomposers. mBio, 10(6).

\section{Acknowledgements}

We gratefully acknowledge financial support from the Laboratory of Excellence ARBRE (ANR-11-LABX0002-01). Special thanks go to Jérôme Balesdent and Matthias Cuntz for their advice.

\section{Author contributions}

J.S.-M., M.B., L.S.-A. and D.D. designed the model. J.S.-M. and M.B. formulated the model equations. J.S.-M. implemented the numerical code. J.S.-M., M.B. and D.D. analysed the model outputs with feedback from L.S.-A., E.G. and F.M. to ensure the ecological relevance of the scenarios. J.S.-M. and D.D. wrote the present article with critical inputs from M.B., L.S.-A., E.G. and F.M.. All authors gave final approval for publication.

\section{Additional information}

A video illustrating lignocellulose degradation in scenario 3 is available as a supplementary file entitled C-STABILITY_lignocellulose.mp4. 